\title{
(In)Justiça escolar: estaria em xeque a concepção clássica de democratização da educação?
}

Ione Ribeiro Valle'

\section{Resumo}

Este trabalho tem como objetivo examinar perspectivas clássicas e contemporâneas a respeito da escola que têm como alvo a igualdade de oportunidades e a meritocracia escolar. Partindo do pressuposto segundo o qual os conceitos de justiça e de justiça escolar gravitam em torno de determinadas concepções, recorremos primeiramente a duas abordagens teóricas. A primeira delas é baseada no pensamento de John Rawls (1921-2002), especificamente no que concerne à noção de justiça como equidade. A segunda abordagem teórica é a de Michael Walzer (1906-1981), autor que defendeu a ideia de uma sociedade complexamente igualitária, na qual a educação figura como uma das esferas da justiça. Em seguida, debruçamo-nos sobre a noção de injustiça, tendo como referência as reflexões de Barrington Moore Júnior (1913-2005), construídas a partir de um estudo rigoroso das condições sociais e históricas nas quais a indignação moral manifesta-se com maior intensidade ao longo dos séculos XIX e XX, e de François Dubet (1946-) que, pautando-se em um estudo qualitativo de grande fôlego, examina os sentimentos de injustiça a partir do embate entre os princípios de igualdade, mérito e autonomia. É no quadro dessas discussões que o desencantamento face às políticas educacionais voltadas à democratização da educação torna-se mais radical e que as injustiças tornam-se mais evidentes, menos toleradas e anunciam a necessidade de construção de uma escola justa.

\section{Palavras-chave}

Justiça - Sentimentos de injustiça - Justiça escolar - Igualdade de oportunidades - Meritocracia escolar. 


\title{
School (in)justice: is the classical concept of education democratization cornered?
}

Ione Ribeiro Vallel

\begin{abstract}
This work aims to examine classical and contemporary perspectives on school that pursue equality of opportunities and school meritocracy. Based on the assumption that the concepts of justice and school justice revolve around certain conceptions, we primarily used two theoretical approaches. The first of them is based on John Rawls' (1921-2002) thinking, particularly concerning the notion of justice as equity. The second theoretical approach is that of Michael Walzer (1906-1981), an author who advocated the idea of a complex equality in society, with education as one of its spheres of justice. Next, we examine the notion of injustice, based on the reflections of Barrington Moore Junior (1913-2005), which are built from a thorough study of the social and historical conditions where moral outrage is most intensely expressed over the nineteenth and twentieth centuries, and the reflections of François Dubet (1946-), who relies on extensive qualitative research to examine the feelings of injustice arising from the conflict between the principles of equality, merit and autonomy. It is within the frame of such discussions that the disillusion with educational policies oriented to education democratization becomes more radical, and injustices become more evident, less tolerated and announce the necessity to build a just school.
\end{abstract}

\section{Keywords}

Justice - Feelings of injustice - School justice - Equality of opportunities - School meritocracy.

I- Federal University of Santa 
O pesquisador só pode chegar depois da festa, quando os lampiões foram apagados e os cavaletes retirados, e com um produto que não tem mais nenhum dos charmes do impromptu. Pierre Bourdieu

As últimas décadas têm imposto grandes desafios aos pensadores e administradores da educação escolar e, consequentemente, propiciado interessantes objetos de reflexão aos sociólogos. Ao invés de deter-se apenas às continuidades, às regulações, às relações entre dominados e dominantes - posições que têm predominado nas análises -, os sociólogos da educação dirigem cada vez mais sua atenção às descontinuidades, às singularidades, às práticas dos atores, agentes ou sujeitos, sendo estimulados a restituir a complexidade efetiva de suas escolhas, de suas razões de agir, da parte de liberdade que ainda resta para suas condutas.

Esses avatares sociais, econômicos, políticos e culturais abalam princípios e pilares das sociedades modernas, tais como a justiça, a democracia, a igualdade, a liberdade, a meritocracia, reavivando velhas tensões entre o singular e o universal, o indivíduo e a sociedade, o bem e o bom, a quantidade e a qualidade. Para enfrentar as incertezas, as contradições e as perplexidades desse início de milênio, recursos educacionais vêm sendo mobilizados, tanto no âmbito dos países quanto no plano das políticas de globalização.

Estamos diante de um quadro de implosões sociais espetaculares (PETITAT, 1998a), marcado por processos de quebra da estandardização. Como nos mostra Martuccelli (2010a, p. 2), assiste-se, "após um primeiro e longo período de industrialização de massa, a um novo avatar na produção da singularidade”. Assim sendo, novas questões são acrescentadas à agenda dos sociólogos da educação e velhas questões precisam ser ressignificadas: como enfrentar as desigualdades e resistir às práticas de reprodução social? Como se posicionar face à unidade da ciência e à pluralidade das culturas? Que fins deve perseguir a escola? Que saberes ensinar? Como distinguir a meritocracia escolar tal como a percebem os indivíduos da meritocracia escolar idealizada? Como formar o corpo docente e se preparar para o avanço sem precedentes da tecnologia?

Retomar essas indagações supõe recuperar os fundamentos que têm orientado os movimentos de escolarização das sociedades democráticas e que remetem a uma imagem idílica da escola, concebida como uma instituição naturalmente integrada, que une harmoniosamente as atividades de seus membros em torno de fins universais e que preconiza uma função pedagógica única, de hierarquização dos papéis e condutas. Essa imagem - latente nas políticas e reformas educacionais, nas diretrizes curriculares, nos programas de formação docente, nas manifestações de professores e administradores - nunca refletiu a dura realidade dos sistemas de ensino. Ao contrário, representa uma norma (um padrão) desejável, que idealiza um projeto educacional com vistas a ser consensual.

Vale lembrar que a sociedade tem depositado grandes expectativas na democratização do ensino, conceito que define princípios, fins e justifica ações administrativas e pedagógicas diversificadas. Contudo, sabe-se que essa noção não dá mais conta da complexidade que envolve os diversos níveis escolares, nem da heterogeneidade dos que a buscam.

Desde os estudos críticos, identificados principalmente nas análises reprodutivistas ${ }^{1}$, que consideraram a escola como reprodutora das estruturas dominantes, sabemos que ela preenche diferentes funções, na medida em que estabelece e persegue objetivos distintos, segundo o nível escolar, a rede de ensino, o tipo de formação profissional, a condição social, econômica e cultural dos alunos.

Esse é o caso da educação escolar brasileira, que está cercada de paradoxos: ao mesmo tempo em que se comemora, desde 1988, a conquista jurídica do direito à educação para todos,

1- Os estudos de Pierre Bourdieu têm sido situados como uma das principais fontes da abordagem reprodutivista, sobretudo sua obra, em coautoria com Jean-Claude Passeron, A reprodução (publicada na França em 1970 e no Brasil em 1975). 
[...] persistem o baixo desempenho dos alunos, o abandono precoce, a exclusão de grandes contingentes populacionais, a segregação escolar no interior dos próprios sistemas de ensino. (VALLE; RUSCHEL, 2009, p. 180)

Seria possivel pensar as transformações históricas a partir do campo educacional? Não que se deva pensá-las unicamente a partir dele, pois muitas delas podem ser estranhas à educação. A escolha desse campo explicita os limites da reflexão a que nos propomos aqui. Parece-nos evidente que outras perspectivas epistêmicas sejam não apenas legítimas como indispensáveis. Como sublinha Bourdieu (2011, p. 208):

[...] o protocolo científico não tem a bela clareza do discurso do bom senso para aquele a quem não é difícil ser simples uma vez que ele sempre começa por simplificar.

Nessa perspectiva, toda reflexão sobre o que seria uma escola justa deve ir além das abordagens decorrentes da imediatidade dos fatos, de enigmas mais que problemas, que fazem apelo a posicionamentos totais e definitivos mais do que a análises necessariamente parciais e revisáveis.

Partindo do pressuposto de que os conceitos de justiça e de justiça escolar gravitam em torno de determinadas concepções, recorremos ao debate e aos embates de abordagens sociológicas contemporâneas, tendo por base os estudos de John Rawls e de Michael Walzer. Em seguida, debruçamo-nos sobre algumas reflexões relativas à noção de injustiça, a partir dos estudos de Barrington Moore Júnior e de François Dubet. Finalmente, examinamos perspectivas que têm como alvo dois princípios fundadores dos movimentos de escolarização e de democratização do acesso à escola: a igualdade de oportunidades e a meritocracia escolar.

\section{Crer na justiça, mas temer as injustiças}

O conceito de justiça apresenta um caráter polimorfo, sendo explicado a partir de diferentes sentidos e abordado por perspectivas epistêmicas diversas, muito próximas dos usos de senso comum. Dubet (2006) assinala que quando as pessoas falam de justiça ou de injustiça mobilizam categorias filosóficas bastante elaboradas para fundamentar seus propósitos, como se tivessem lido Aristóteles, Kant ou Rawls.

0 termo justiça vem da antiguidade clássica, é reformulado pelos iluministas na perspectiva da racionalidade e chega aos dias de hoje marcado por um profundo relativismo. Segundo Valle (2010, p. 27), os princípios de justiça:

[...] se multiplicam e se diversificam, [...] a motivação pessoal deixa de ser um simples reflexo das expectativas dos outros, a moral não é mais uma realidade dada, direitos e deveres são inseparáveis.

0 conceito de princípio de justiça ganha uma força extraordinária ao longo da primeira metade do século XX, quando eclodem movimentos políticos e sociais de dimensões e tonalidades variadas. Todavia, em razão da ambiguidade situada na sua gênese, o conceito tem estimulado grandes utopias, mas também provocado equívocos e desilusões. Nota-se, portanto, que além do conceito que vem sendo ressignificado sistematicamente, desenha-se um problema de constituição política, econômica, cultural e moral das sociedades contemporâneas de amplidão considerável. Isso porque há uma distância importante entre o ideal de justiça, preconizado, sobretudo no âmbito legal, e sua operacionalização.

Além disso, diversos estudos têm demonstrado que a noção genérica que predominou ao longo do século XX cede lugar a uma série de ambivalentes situações decorrentes de articulações mais complexas entre o singular e o universal (DUBET, 2006): o desejo de justiça 
pode tornar-se uma fonte para a conquista da singularidade ou, ao contrário, a preocupação com a singularidade. Quando se radicaliza, podem-se privilegiar interesses de uns em detrimento de direitos de outros.

Considerando que toda escolha teórica implica restrições de diferentes ordens, procuramos concentrar nossa atenção em quatro obras de autores contemporâneos que têm inspirado, com maior ou menor intensidade, a construção da noção de justiça escolar: as duas primeiras discorrem a respeito da (re)formulação do ideal de justiça e as duas últimas examinam a ameaça decorrente da ambiguidade desse conceito a partir da análise de situações (históricas, políticas e de trabalho) de injustiça.

Embora nossa escolha teórica revele o grau elevado de generalização sobre o qual embasamos nossa reflexão, entendemos que ela permite enfocar esses dois conceitos em uma perspectiva relacional, pois não nos parece possível caracterizar uma escola justa sem ter como referência as bases sociais das injustiças educacionais.

A primeira obra, apontada como uma das mais importantes do pensamento moral da segunda metade do século XX, foi elaborada por John Rawls (2002) e intitulada Uma teoria da justiça. Publicada originalmente em 1971, nessa obra autor desenvolve a noção de justiça como equidade, inspirando-se nas teorias do contrato social. A segunda, intitulada Esferas da justiça: uma defesa do pluralismo e da igualdade, é de Michael Walzer e foi publicada originalmente em 1983. É a ideia de uma sociedade complexamente igualitária que está no centro dessa abordagem que procura redefinir uma moral de fundo aristotélico, fundada em virtudes e não em princípios universais. A terceira, desenvolvida por Barrington Moore Júnior (1987), considerado precursor da sociologia histórica comparada graças à profundidade, precisão e abrangência macrossociológica de seus argumentos, intitula-se Injustiça: as bases sociais da obediência e da revolta. Nessa obra, cuja publicação original é de 1978, sublinhamos alguns pontos-chave voltados fundamentalmente ao sentido de injustiça, construídos a partir de um estudo rigoroso e amplo das condições sociais e históricas nas quais a indignação moral manifestou-se com maior intensidade ao longo dos séculos XIX e XX. A última obra é de François Dubet (2006), um dos sociólogos franceses da nova geração, que vem se destacando por ter estendido suas análises iniciadas no campo da sociologia da educação a outros domínios do conhecimento. 0 livro Injustiças: a experiência das desigualdades no trabalho, marca o caráter polêmico de suas ideias e a maneira instigante como desenvolve seu raciocínio.

Dubet (2006) desenvolve um estudo qualitativo, que abrange de forma articulada diferentes temas: justiça, trabalho, educação, identidades profissionais, trajetórias escolares, impactos da formação profissional nos sentimentos dos trabalhadores. A discussão teórica de fundo é a oposição entre justiça e injustiça, vista a partir do embate entre os princípios de igualdade, mérito e autonomia.

\section{O ideal de justiça}

John Rawls (2002) argumenta em favor de uma nova concepção contratual da justiça - percebida como política, não metafísica. Essa concepção é apresentada por meio de um esquema normativo de pensamento que correlaciona o racional e o razoável, o bem e o justo. Sua teoria não propõe uma igualdade plena entre os homens, mas princípios que alicerçariam uma democracia constitucional:

As instituições são justas quando não se fazem distinções arbitrárias entre as pessoas na atribuição de direitos e deveres básicos e quando as regras determinam um equilíbrio adequado entre reivindicações concorrentes das vantagens da vida social (RAWLS, 2002, p. 6).

Segundo ele, uma sociedade democrática deve combinar o princípio da liberdade, que determina um acesso igual ao maior número de 
liberdades individuais, e o princípio da diferença, que se articula ao princípio da reparação. Esses três princípios definem as regras da justiça social, as quais devem levar a uma compensação das desvantagens socioeconômicas dos menos favorecidos e fazer com que o princípio da igualdade de oportunidades se efetive.

Convencido de que o justo precede o bem e de que são as circunstâncias contextuais que determinam cada procedimento, o autor defende a existência de certas desigualdades socioeconômicas, mas não considera justo que uns tenham menos para que outros prosperem. Assim, as tendências e inclinações dos homens não são tomadas como fatos adquiridos, qualquer que seja a sua natureza, para depois se buscar a melhor maneira de realizá-las. Ao contrário, para Rawls (2002, p.34):

Seus desejos e aspirações são restringidos desde o início pelos princípios de justiça que especificam os limites que os sistemas humanos de finalidades devem respeitar.

Ele não vê, portanto, injustiça na obtenção de benefícios maiores por alguns, desde que haja formas de compensação cujo objetivo seja a melhor situação de outros.

Conforme Meuret (2000) e Bolívar (2005), a escolarização não tem grande relevância na obra de Rawls, pois não integra sua lista de bens sociais primários. Entretanto, mesmo sem incluir diretamente a educação em seu esquema, pode-se entendê-la como um direito social fundamental ao desenvolvimento das pessoas livres e iguais. Notamos que Rawls, sobretudo na formulação do princípio da diferença, argumenta em favor da justa igualdade das oportunidades, evocando explicitamente, e com certa frequência, uma equitativa distribuição da educação, fato que nos leva a inferir que a escola figura como uma instituição social necessária à criação de condições para o progresso social. Mas é principalmente a influência de sua teoria na definição das políticas educacionais atuais, particularmente em relação à noção de justiça como equidade, nas quais as medidas compensatórias ou reparadoras ocupam um lugar de destaque, que nos permite situá-lo na base do movimento de construção de uma escola justa.

Michael Walzer (2003), por sua vez, dedica-se à formulação de uma concepção de justiça que entende ser mais ampla e plural, na qual o estado se compromete com a benevolência. Sua reflexão é marcada pela reação à abordagem rawlsiana. Segundo ele, não se pode esperar que:

[...] os cidadãos governem e sejam governados em revezamento, mas que governem em uma esfera e sejam governados em outra - donde 'governar' não significa que exerçam o poder, mas que desfrutem uma parcela maior do que outras pessoas de um bem qualquer, a ser distribuido (WALZER, 2003, p. 440).

Sua teoria, portanto, supõe a eliminação apenas de certas desigualdades, próprias de cada época e lugar, pois o problema, segundo o autor, não estaria na desigualdade em si, mas nas relações de dominação: "O que a justiça requer é que nenhum bem social possa servir de meio de dominação" (WALZER, 2003, p. 12).

Justiça e igualdade são, para Walzer, artefatos filosóficos, o que o leva a criticar a noção de igualdade, cuja raiz lhe parece negativa. 0 autor observa que, ao longo dos tempos, toda situação de igualdade tem gerado desigualdades e que a arte da diferenciação, característica da justiça distributiva, é geradora de conflitos sociais.

Sua reflexão apoia-se na ideia de um pluralismo moral sem, contudo, renunciar à possibilidade de um consenso. Para conciliar universalidade e diversidade, Walzer distingue uma moral mínima (thin) de uma moral máxima (thick). Enquanto a última corresponde às morais concretas, aos sistemas complexos e desenvolvidos marcados pela diversidade e pelo conflito, a moral mínima pauta-se em um núcleo de princípios comuns a serem partilhados por todos os seres humanos. 
Diferentemente de Rawls, a educação é, para Walzer, uma das esferas da justiça. Por essa razão, sua perspectiva teórica assume uma grande importância nas (re)definições das políticas educacionais atuais e, evidentemente, nas discussões a respeito do que seria uma escola justa. 0 principal alvo da crítica à sua teoria é a argumentação a favor da igualdade de oportunidades e do ideal meritocrático ${ }^{2}$.

\section{A ameaça da ambiguidade}

Barrington Moore Júnior conduz sua reflexão a partir de algumas indagações centrais: que tendências históricas têm fundado as noções de injustiça e de justiça? De onde essas ideias provêm? Que fatores provocam tão amplas e profundas variações de apreensão e de ação entre grupos de trabalhadores? 0 autor reconhece tratar-se de questões complexas "que a ciência não pode colocar porque ela se refere ao modo como as coisas são, não à maneira como deveriam ser" (MOORE JÚNIOR, 1987, p. 20).

Moore Júnior dedica-se a analisar, tendo por base os contextos históricos da Alemanha e da Rússia, mecanismos psicológicos e sociológicos que levam alguns indivíduos a resistir à injustiça ou a defınir sua situação como injusta, mobilizando-se para enfrentá-la. 0 autor parte do pressuposto de que o termo injustiça está cercado por um relativismo moral, decorrente de conflitos sobre valores ou de pressupostos relativos ao bem e ao mal. 0 autor reafirma, portanto, o caráter obscuro do conceito evidenciado nas obras anteriores.

Para elaborar seus principais argumentos, elege dimensões no desencadeamento dos sentimentos de injustiça, referindo-se, primeiramente, à autoridade e ao desafio à autoridade. Ao discorrer longamente acerca desse tema, conclui que "toda sociedade humana dispõe de uma concepção de punição injusta e de um

2 - Para Walzer (2003), a meritocracia possibilita uma distribuição justa dos postos de trabalho. Idealizada pelo movimento revolucionário francês, supõe que os cargos sejam ocupados pelos mais qualificados, cujas prerrogativas devem ser limitadas. Esses limites seriam definidos no âmbito das esferas da justiça. modo específico de decidir que a punição é injusta" (MOORE JÚNIOR, 1987, p. 57).

Outra dimensão discutida pelo autor é a de divisão do trabalho, a qual, apesar de ser bastante variável de uma sociedade a outra, está presente em todas elas. Ora, qualquer ordem social confronta-se com conflitos de interesses individuais que podem levar os indivíduos a não aceitarem de forma tranquila as normas estabelecidas pelo contrato social vigente. Essa não aceitação ocorre, sobretudo, quando as compensações materiais são mais frágeis, podendo despertar a indignação moral e um sentimento de injustiça social.

Por fim, Moore Júnior (1987), em um tópico chamado a distribuição de bens e serviços: nas permutas de igualdade, identifica o sentimento que emerge do conflito inerente às demandas de igualdade e às justificações dos dominantes para as desigualdades. Esse conflito desvela lógicas da desigualdade social que podem tornar-se fonte da ira moral e da recusa do sofrimento e da opressão, fomentando assim o senso de injustiça social:

\section{A forma de crítica realmente subversiva tem início quando as pessoas perguntam se uma função social específica necessita realmente ser desempenhada, se reis, padres, capitalistas e mesmo burocratas revolucionários não seriam desnecessários à sociedade humana (MOORE JÚNIOR, 1987, p. 687).}

Por fim, cabe examinarmos a obra de François Dubet (2006), autor que parte do pressuposto de que a poliarquia dos princípios de justiça abre um espaço de debates ainda mais inesgotável quando tais princípios ganham colorações distintas em função dos contextos e dos interesses. Segundo ele, as críticas dirigidas às condições e às relações de trabalho se impõem como uma força particular no quadro da divisão do trabalho, pois é o local em que se cristaliza um conjunto de mecanismos e de relações sociais particularmente propícias à manifestação dos sentimentos de injustiça. 
Assim, o autor indaga: qual seria essa arqueologia do trabalho, essa sedimentação de estratos de significações na experiência do trabalho, ao considerar o estatuto, o valor de troca e a atividade criativa como suas naturezas? Dubet (2006) procura responder essa indagação a partir das representações de trabalhadores de diferentes áreas, por meio da análise de três princípios de justiça: a igualdade, o mérito e a autonomia.

Conceituar injustiça supõe, inicialmente, definir o conceito a partir das maneiras pelas quais os atores o concebem e o põem em prática. Isso porque, como coloca Dubet (2006, p.9):

[...] se nenhum de nós consegue explicitar claramente o que é justo e o que deveria ser um mundo justo, todos sabemos o que é injusto e porque.

Mas, para melhor compreender o conceito de justiça, faz-se necessário conhecer suas formas de articulação com problemas relacionados ao direito, ao poder e ao reconhecimento.

Considerando o caráter contraditório desse conceito, uma vez que ele engendra um conjunto infinito de críticas e remetem a contestações diversas, Dubet (2006) observa que os trabalhadores desenvolvem indubitavelmente sentimentos de injustiça nos contextos sociais em que os mesmos se formam. Além disso, nota que os trabalhadores se associam mais ou menos a posições sociais, a situações de trabalho, a tipos de organização do trabalho e de gerenciamento. Enfım, fica evidente que se podem estabelecer ligações entre a distribuição social dos sentimentos de injustiça, a experiência de vida dos trabalhadores e seus status sociais. Considerando que as injustiças podem tanto destruir quanto reforçar a subjetividade dos indivíduos, "todos os princípios de justiça acabam parecendo cruéis”, e um mundo justo só pode ser pensado em termos de arranjos locais entre princípios contraditórios, uma vez que os indivíduos se apoiam em princípios estáveis para fundar suas boas razões de agir.

Assim, a questão que se coloca para os sociólogos é como definir uma sociedade justa: seria aquela que permite aos trabalhadores constituírem-se como sujeitos capazes de dizer onde está sua dignidade, como se forja uma vida boa e aceitável, como resistir ao encadeamento das injustiças?

Da mesma maneira, o desafio que se apresenta hoje para os sociólogos da educação é designar uma escola justa: seria aquela que articula igualdade meritocrática das oportunidades, igualdade distributiva das oportunidades, igualdade social das oportunidades e igualdade individual das oportunidades?

Pensamos que quando os valores (con) sagrados (do projeto republicano) não fundam mais a sociedade e não caracterizam mais a escola, como sonhara Durkheim (1978), em obra originalmente datada de 1922. Quando as desigualdades sociais, percebidas e sentidas como injustas, contrapõem-se ao ideal de justiça, torna-se necessário repensar esses princípios.

\section{Justiça escolar: um conceito em construção}

A noção mágica da escola democrática, que transforma dons e talentos individuais em virtudes sociais que se convertem em benefícios coletivos, confronta-se hoje com uma visão pessimista, fruto não de uma falta de crédito na educação escolar, mas do reiterado fracasso das políticas educacionais. Por essa razão, a noção de justiça escolar aparece como um apelo à criatividade, à mudança, à mobilização, como um avatar das políticas para a educação e, dessa forma, desafia pesquisadores, professores e administradores dos sistemas de ensino.

Trata-se de um conceito em construção, mergulhado, portanto, em incertezas e ambiguidades. A noção de justiça escolar vem se firmando no cruzamento de múltiplas tensões e tendências, influenciadas pela decomposição/ recomposição de diferentes campos do conhecimento. Assim, neste trabalho propomo-nos a desenvolver uma reflexão a partir dos dois princípios que têm orientado os discursos, as políticas e as práticas educacionais ao longo do 
século XX: a igualdade de oportunidades e a meritocracia escolar. 0 primeiro é considerado como um dos princípios mais evidentes e mais complexos da justiça; o segundo é incontornável na imagem de um mundo justo, no qual cada um seria recompensado em função de seu mérito, de seus esforços e, consequentemente, dos dos resultados alcançados (DUBET, 2006, 2008).

\section{A igualdade de oportunidades}

0 princípio de igualdade de oportunidades é central nas teorias contemporâneas da justiça, como vimos em Rawls e Walzer. Embora, em tese, a igualdade de oportunidades seja chave na consolidação das políticas de democratização, nunca garantiu que, em nível igual de talento, motivação e competência, todos tenham as mesmas perspectivas de sucesso, independentemente do meio social, da educação familiar e dos processos de socialização. Além disso, nas sociedades marcadas por desigualdades profundas, tal como no Brasil, o sonho da igualdade de oportunidades está longe de se tornar realidade. Ele suporia generalizar o acesso aos bens sociais primários, conciliar universalidade e diversidade, promover uma moral mínima, eliminando assim todas as diferenças que impedem a manifestação dos méritos individuais.

Segundo Walzer (2003, p. 271), “a justiça não se relaciona só com os resultados, mas também com a vivência da educação". Seria de se esperar que uma política da igualdade de oportunidades garantisse os recursos necessários, de maneira que os resultados obtidos correspondam unicamente ao esforço pessoal e não às circunstâncias existenciais de cada um. Para ele, esse princípio tem um antes e um depois: antes de ingressar na competição "todos os ponteiros devem ser zerados" (WALZER, 2003, p. 271). Isso supõe uma forte intervenção social, mas, uma vez inserido na competição, cada um deve assumir plenamente a responsabilidade por suas realizações.

Na obra de Moore Júnior (1987), mas sobretudo na de Dubet (2006), o princípio da igualdade de oportunidades ${ }^{3}$ figura como uma promessa das sociedades democráticas que conta com grande legitimidade. Esse princípio não supõe apenas a promoção na escala social, mas visa a permitir que cada um possa frutificar seus dons. São as políticas de equidade, no sentido atribuído por Rawls (2002), que se traduzem no imperativo da educação gratuita e universal, dos sistemas de bolsas e cotas, das modalidades de avaliação e seleção, dos veredictos escolares, da distinção dos diplomados, da hierarquização das carreiras profissionais, que fundamentam o dogma meritocrático de que todo desenvolvimento da escolarização é justo e eficaz (DURU-BELLAT, 2006).

No entanto, apesar da diversificação de ações de democratização e de inclusão, as desigualdades fracionam-se, multiplicam-se e diversificam-se no âmbito da escola, do mundo do trabalho, das hierarquias sociais, sem que se consiga desmontar o mecanismo e a lógica que elas ocultam. Assim, a contradição entre o princípio da igualdade de todos os alunos e a necessidade de torná-los desiguais passa despercebida, pois tudo o que coloca em xeque a compatibilidade entre esses dois fatores é enviado para fora do santuário escolar. Enfım, essa contradição, que a configuração dos sistemas de ensino apresenta como antinomias intransponíveis (democratização/seleção, quantidade/ qualidade, público/privado), persiste apesar do esforço para superar as tensões entre exigências sociais opostas ou entre os fins propostos e os meios indispensáveis para realizá-los.

Mas é no quadro das discussões a respeito das ideologias meritocrática que 0 desencantamento face às políticas educacionais torna-se mais radical e que as injustiças tornam-se cada vez mais evidentes e menos toleradas, de maneira a anunciar a necessidade de construção de uma escola justa:

3- É importante assinalar que as críticas ao princípio da igualdade de oportunidades têm sido objeto de estudos dos sociólogos da educação desde a década de 1960. As perspectivas mais radicais foram desencadeadas por Bourdieu e Passeron (1964 e 1970) e foram seguidas por outras, vindas de diferentes matrizes teóricas. 
Não uma escola perfeita numa sociedade perfeita, destinada a indivíduos perfeitos, mas uma escola tão justa quanto possivel ou, melhor ainda, uma escola o menos injusta possível. (DUBET, 2008, p. 9)

\section{A meritocracia escolar}

Tanto entre pesquisadores quanto entre políticos e administradores, a meritocracia constitui um dos temas mais clássicos, por referir-se a um princípio que harmoniza diferenças individuais e desigualdades sociais, promovendo o equilíbrio e a eficácia global da sociedade: todo indivíduo é estimulado a explorar ao máximo seus talentos, a ocupar o lugar que lhe conferem seus dons, sua vocação, seu esforço, sua destreza, sua qualificação, sua experiência. Sem o mérito não haveria outra maneira, senão a do nascimento, - que se ancora em propriedades herdadas - de distribuição dos indivíduos em uma escala de estratificação social. Ele é considerado, portanto, como a única maneira legítima de produzir desigualdades justas. Esse princípio, único que pode tornar admissíveis as diferenças de remuneração, prestígio e poder que determinam tanto o sucesso quanto o fracasso escolar, figura, desde o final do século XIX, como a única via ao mesmo tempo justa e eficaz de repartir os lugares (desiguais) nas sociedades atuais (DURU-BELLAT, 2006). Ele vem, ao longo dos tempos, dando sentido aos movimentos de massificação do ensino, pois se supõe que, ao conquistar a igualdade jurídica de acesso aos bens educacionais, desapareçam os obstáculos ao progresso individual.

As críticas à meritocracia vêm de diferentes direções, como mostram Kreimer (2000) e Valle e Ruschel (2010). No entanto, detemo-nos aqui nos trabalhos de autores que se referem especificamente à meritocracia escolar e mostram como esse princípio de justiça legitima-se. A escola, que goza de uma autonomia relativa, lembram Duru-Bellat e Zanten (1992), e que se constitui na ponta de lança dessa ideologia, deve transmitir aos alunos saberes essencialmente legítimos, ministrados por professores competentes e realizar, a partir dessa base, uma seleção intrinsecamente meritocrática. Estabelece-se, assim, o que Bolívar (2005) nomeia de aliança meritocrática entre as categorias altamente dotadas de capital cultural e a profissão docente.

Sabe-se que, desde o início da escolarização, os percursos diferenciados são explicados por fatores estritamente relacionados aos talentos e dons individuais, embora se reconheça que o mérito escolar não é distribuído de maneira aleatória e que, frequentemente, possibilita a transformação de determinações sociais em talentos pessoais: "0 mérito pode ser uma espécie de darwinismo social mascarado por algumas virtudes" (DUBET, 2009, p. 263). Assim, o mérito só tem sentido em uma sociedade que valoriza algumas capacidades mais que outras, não sendo transparente, nem neutro, como vislumbravam os idealizadores do projeto republicano. Além disso, ele não é facilmente mensurável, nem pode ser identificado a priori, pois somente se pode saber o que cada um merece depois de ver o que conseguiu.

Para Bourdieu (1989), esse meritocratismo do êxito escolar ou da competência científica justifica os veredictos escolares e suas consequências sociais, exercendo um papel crucial na reprodução social. 0 autor chega a qualificá-lo como um verdadeiro racismo da inteligência e lembra que para que a magia meritocrática possa legitimar-se é necessário que todos - dominados e dominantes - acreditem nela.

As pesquisas referentes aos aspectos subjetivos das desigualdades têm demonstrado que os dominantes impõem a meritocracia como esquema de interpretação e de justificação da realidade; os dominados, ao contrário, aprendem a aceitar as desigualdades e a desvalorização de si (MARTUCCELLI, 2010a e b; DURU-BELLAT, 2002; DUBET; MARTUCCELLI, 1996).

Enfim, uma reflexão prospectiva a respeito da escola, tal como a que se vislumbra na noção de justiça escolar, que supõe transformações nas políticas para a educação voltadas à democratização da educação, não pode ignorar 
as contradições que envolvem uma instituição destinada, historicamente, a responder a interesses produzidos no embate entre diferentes princípios. Enquanto a educação, em termos ideais, identifica-se com a justiça social por estar ligada ao princípio liberal da igualdade, devendo atender a necessidades gerais e funcionais da sociedade, a escola é acusada de privilegiar os interesses das classes mais favorecidas ao colocar em prática mecanismos de seleção e de classificação, promotores de um conjunto significativo de injustiças.

Vale lembrar, com Bourdieu (1989), que é preciso tomar consciência dos efeitos, muitas vezes perversos, dos veredictos escolares, que fazem com que os êxitos tenham um efeito de consagração e os fracassos transformem-se em condenação. Importante salientar, ainda, o pensamento de Dubet (2008), ao assinalar que a meritocracia torna-se intolerável quando associa o orgulho dos vitoriosos ao desprezo pelos perdedores mas, apesar disso, goza de grande legitimidade (DURU-BELLAT; TENRET, 2009). Assim, a adesão dos indivíduos às hierarquias escolares e ao culto escolar da hierarquia deve-se ao lugar que a escola lhes destina em sua própria hierarquia, de maneira que a experiência escolar se torna central na produção de sentimentos de justiça e de injustiça.

Não se pode esquecer, finalmente, que a justiça implícita no mérito - e sobretudo no mérito escolar - sofre as consequências das desigualdades situadas fora da escola, fazendo com que o universo da competição meritocrática $^{4}$ não seja transparente, mas um espaço onde se cruzam interesses, na maioria das vezes contraditórios. Não se pode deixar de conside-

4 - Talcott Parsons $(1970,1973)$ considera que a competição meritocrática permite 0 compartilhamento de valores comuns, a adesão de todos à ideologia do mérito individual e à crença na igualdade das oportunidades, o que, numa sociedade competitiva e aberta, torna possivel superar a frustração decorrente do fracasso. A competição meritocrática supõe a existência de ganhadores e de perdedores, mas para que a coesão social continue possível é necessário, antes de tudo, que todos reconheçam como equitativas as regras do jogo e sejam persuadidos de que as vantagens conquistadas por cada um refletem as diferenças interindividuais de talento e mérito. rar, no entanto, que o modelo de justiça social baseado no princípio meritocrático goza cada vez mais de legitimidade nas sociedades democráticas, nas quais a igualdade jurídica de todos os indivíduos é permanentemente reafirmada.

Como se pôde ver, é na convergência de diferentes perspectivas epistemológicas que emerge a noção de justiça escolar. Trata-se de uma noção que supõe reconhecer a contribuição da história para os estudos sociológicos não como um interesse de antiquário, como sublinha Bourdieu (2001, p. 37), mas como um procedimento que permite: 1) entender porque se compreende e como se compreende; 2) evidenciar a necessidade de elaboração de sínteses dos estudos realizados, buscando produzir um conhecimento mais adensado sobre os sistemas de ensino; e 3) mostrar a importância das análises comparativas entre os estados da federação e o plano internacional, focalizando problemas comuns aos demais sistemas educacionais.

A reflexão a respeito do que seria uma escola justa não pode prescindir, portanto, da produção teórica construída pela sociologia, nas suas mais diferentes subdivisões: a) a sociologia da educação ou da escola (DURUBELLAT; ZANTEN, 1992; DURU-BELLAT, 2002), que abrange um campo vasto e variável; b) a sociologia da experiência escolar (DUBET; MARTUCCELLI, 1996), que alerta para as diferentes formas e espaços de socialização; c) a sociologia do fracasso escolar (LAHIRE, 2000), que coloca em perspectiva as desigualdades sociais face à escola; d) a sociologia do indivíduo (MARTUCCELLI, 2010a e b), que leva em conta o crescimento estrutural da singularidade assim como o segredo simbólico que oculta a natureza das representações mentais (PETITAT, 1998b); e) a sociologia das profissões (DUBAR; TRIPIER, 1998), que analisa o espaço escolar a partir do cruzamento de múltiplas identidades; f) a sociologia dos saberes escolares (VALLE, 2008), que permite lançar um novo olhar sobre a reprodução cultural; e g) a sociologia da família, da juventude, da infância. 


\section{Referências}

BOLÍVAR, Antonio. Equidad educativa y teorías de la justicia. REICE - Revista Electrónica Iberoamericana sobre Calidad, Eficacia y Cambio en Educación, v. 3, n. 2. Disponível em: <http://www.rinace.net/arts/vol3num2/art4.pdf>. Acesso em: 20 fev. 2007.

BOURDIEU, Pierre; PASSERON, Jean-Claude. Les héritiers: les étudiants et la culture. Paris: Minuit, 1964.

A reprodução: elementos para uma teoria do sistema de ensino. 2. ed. Rio de Janeiro: Francisco Alves, 1982. (Trabalho original publicado em 1970).

BOURDIEU, Pierre. La noblesse d’État: grandes écoles et esprit de corps. Paris: Minuit, 1989.

0 poder simbólico. Rio de Janeiro: Bertrand Brasil, 2001.

. Homo academicus. Florianópolis: Editora da UFSC, 2011.

DUBAR, Claude; TRIPIER, Pierre. Sociologie des professions. Paris: Armand Colin, 1998.

DUBET, François; MARTUCCELLI, Danilo. À l'école: sociologie de l'expérience scolaire. Paris: Seuil, 1996.

DUBET, François. Injustices: l'expérience des inégalités au travail. Paris: Seuil, 2006.

. 0 que é uma escola justa?: a escola das oportunidades. São Paulo: Cortez, 2008.

. Le travail des sociétés. Paris: Seuil, 2009.

DURKHEIM, Émile. Educação e sociologia. 11. ed. São Paulo: Melhoramentos, 1978. (Trabalho original publicado em 1922).

DURU-BELLAT, Marie; ZANTEN, Agnès Henriot-Van. Sociologie de l'école. Paris: Armand Colin, 1992.

TENRET, Élise. L'emprise de la méritocratie scolaire: quelle légitimité? Revue Française de Sociologie, v. 50, n. 2, p. 229-258, 2009.

DURU-BELLAT, Marie. L'inflation scolaire: les désillusions de la méritocratie. Paris: Seuil, 2006.

. Les inégalités sociales à lécole: genèse et mythes. Paris: PUF, 2002.

KREIMER, Roxana. História del mérito. 2000. Disponível em: <http://www.oocities.org/filosofialiteratura>. Acesso em: 07 mar. 2007.

LAHIRE, Bernard. Culture écrite et inégalités scolaires: sociologie de l'échec scolaire à l'école primaire. Lyon: Presses Universitaires, 2000.

MARTUCCELLI, Danilo. Grand résumé de la société singulariste. SociologieS, Paris, Armand Colin, 2010a. Disponível em: <http:// www.sociologies.revues.org/index3344.html>. Acesso em: 25 fev. 2011.

. Philosophie de l'existence et sociologie de l'individu: notes pour une confrontation critique. SociologieS, Paris: Éditions

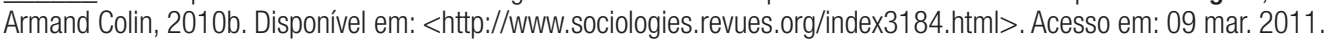

MEURET, Denis. L'équité en éducation selon les théories de la justice. In: ALCOUFFE, Alain et al (Orgs.). Efficacité versus équité en économie sociale. Paris: L'Harmattan, 2000. (Coleção Logiques économiques, v. 1). Disponível em: <http://www.u-bourgogne. fr/LABO-IREDU/2000/00064.pdf>. Acesso em: 10 mar. 2007.

MOORE JÚNIOR, Barrington. Injustiça: as bases sociais da desobediência e da revolta. São Paulo: Brasiliense, 1987. (Trabalho original publicado em 1978). 
PARSONS, Talcott. Uma visão geral. In: (Org.). A sociologia americana: perspectivas, problemas, métodos. São Paulo:

Cultrix, 1970, p. 366-383.

PARSONS, Talcott. Sociétés, essai sur leurs évolutions comparées. Paris: Dunod, 1973.

PETITAT, André. Éducation et implosion sociale. Revue Française de Pédagogie. Paris, n. 124, p. 5-11, jul./set. 1998a.

Secret et formes sociales. Paris: PUF, 1998b.

RAWLS, John. Uma teoria da justiça. 2. ed. São Paulo: Martins Fontes, 2002. (Trabalho original publicado em 1971).

VALLE, Ione Ribeiro. 0 lugar dos saberes escolares na sociologia brasileira da educação. Currículo sem Fronteiras, v. 8, n.1, p. 94-108, jan./jun. 2008.

. Justiça na escola: das desigualdades justas à igualdade sem adjetivos! In: ; SILVA, Vera Lúcia Gaspar da; $\overline{\mathrm{DAROS}}$ Maria das Dores (Orgs.). Educação escolar e justiça social. Florianópolis: UFSC/NUP, 2010. p. 19-48.

RUSCHEL, Elizete. A meritocracia na política educacional brasileira (1930-2000). Revista Portuguesa de Educação, Porto: Instituto de Educação e Psicologia da Universidade do Minho, v. 22, n. 1, p. 179-206, 2009.

Política educacional brasileira e catarinense (1934-1996): uma inspiração meritocrática. Revista Eletrónica de Investigación y Docéncia, v. 3, p. 73-92, 2010.

WALZER, Michael. Esferas da justiça: uma defesa do pluralismo e da igualdade. São Paulo: Martins Fontes, 2003.

Recebido em:12.10.2012

Aprovado em:14.03.2013

Ione Ribeiro Valle é doutora em Ciências da Educação pela Université René Descartes - Paris V - Sorbonne. Professora associada do Centro de Ciências da Educação da Universidade Federal de Santa Catarina (UFSC). Bolsista de produtividade em pesquisa do Conselho Nacional de Desenvolvimento Científico e Tecnológico (CNPq). 